\title{
Sciendo
}

REVIEWS

\section{Systematic approach to celiac disease: a comprehensive review for primary providers}

\author{
PEDRO CORTÉS ${ }^{1}$, DANA M HARRIS ${ }^{1}$, YAN BI ${ }^{2}$
}

\author{
${ }^{1}$ Division of Community Internal Medicine, Mayo Clinic Jacksonville, FL 32224 \\ ${ }^{2}$ Division of Gastroenterology and Hepatology, Mayo Clinic Jacksonville, FL 32224
}

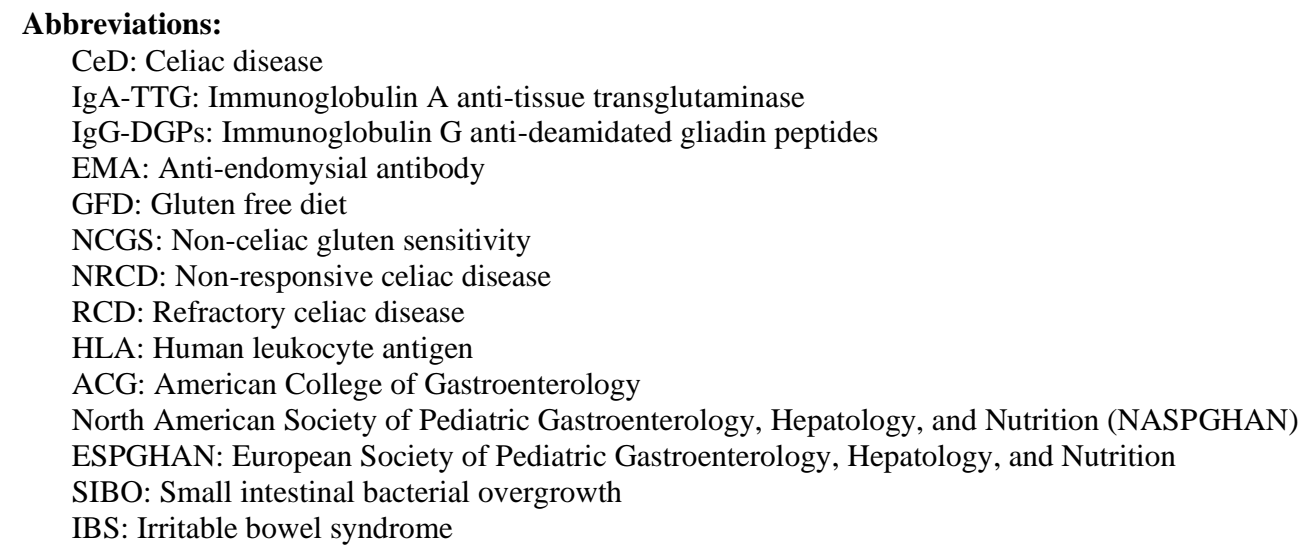

Celiac disease is an immune-mediated illness to gluten exposure in genetically susceptible patients. It is characterized by chronic lymphocytic inflammation of the small bowel leading to villous atrophy and its associated complications. The global prevalence of celiac disease is increasing, due in part to improved screening tests and simplified diagnostic criteria. Novel therapies are being developed and include proteolytic enzymes, sequestering agents, and immunotherapies. A strict gluten-free diet, however, remains the mainstay of treatment. In this comprehensive review, we discuss the epidemiology, definitions, diagnosis, and treatment of celiac disease.

Key words: celiac disease, gluten sensitivity, gluten-free diet, primary care, diagnosis.

\section{INTRODUCTION}

Celiac disease $(\mathrm{CeD})$ is a chronic enteropathy triggered by gluten in genetically predisposed individuals. The illness was first described in 1888 amongst children in London and became treated with dietary modifications, such as following a strict diet of bananas [1]. In 1940, gluten, which refers to the cereal proteins of wheat, barley, and rye, was discovered as the trigger for $\mathrm{CeD}$ [2].

$\mathrm{CeD}$ is a systemic illness that may present in children and adults in various manners. Patients may present with signs of malnutrition, including failure to thrive, short stature, and weight loss, or with symptoms of abdominal pain, chronic diarrhea, or nausea [3]. Extra-intestinal manifestations, including dermatitis herpetiformis, vitamin deficiencies, iron deficiency anemia, aphthous stomatitis, elevated aminotransferases, and neurological manifestations, such as ataxia or seizures, may occur as part of the initial presentation [3].

Gluten contains a high number of proline residues, which make it resistant to proteolytic digestive enzymes [4]. The gluten polypeptides, including gliadin, glutenins, secalin, and hordein, remain undigested and cross the intestinal submucosa through paracellular and transcellular mechanisms [4]. Tissue transglutaminase (TTG) deamidates the gluten polypeptides, making them recognizable by antigen presenting cells (APCs). The APCs present deamidated gliadin peptides on MHC class II molecules, encoded by human 
leukocyte antigen (HLA)-DQ2 or HLA-DQ8 genes, to $\mathrm{T}$ helper cells $\left(\mathrm{T}_{\mathrm{h}} 1\right.$ and $\mathrm{T}_{\mathrm{h}} 2$ cells), initiating an adaptive immune response. Cytotoxic T-lymphocytes (CTLs) and natural killer (NK) cells are recruited, leading to apoptosis of enterocytes and damage of the intestinal submucosa. Cytokines released by $\mathrm{T}_{\mathrm{h}} 2$ cells induce differentiation of B-cells into plasma cells, which produce autoantibodies against TTG and gliadin peptides. The inflammatory milieu causes destruction of the villi leading to villous atrophy.

\section{EPIDEMIOLOGY}

Until recent decades, $\mathrm{CeD}$ had been considered an uncommon illness, mainly affecting children and individuals of European descent [5]. Between 1974 and 2003, the prevalence of CeD increased from $0.21 \%$ (about 1 in 476 patients) to $0.95 \%$ (about 1 in 105 patients) across all patients in the United States [6]. Non-Hispanic white individuals have the highest prevalence of $\mathrm{CeD}$ in the United States compared to Hispanic or African Americans [7]. Similarly, the incidence of $\mathrm{CeD}$ increased in Europe from 5.2 to 19.1 per 100,000 person-years between 1990 and 2011 [8]. The exact reason for the increased incidence and prevalence is unclear, but it is partially due to improved diagnostics and widespread availability of serological testing [9].

\section{RISK FACTORS FOR CED}

Certain genetic and environmental exposures have been implicated as risk factors for CeD. The HLA class II haplotypes DQ2 and DQ8 are necessary but not sufficient for the development of $\mathrm{CeD}$ and contribute $35-40 \%$ to the genetic susceptibility in the development of $\mathrm{CeD}[2,10,11]$. Non-HLA genes contribute about $65 \%$ to the genetic susceptibility [11]. Heritability of CeD is estimated at $87 \%$ based on twin studies, which have shown high concordance in monozygotic twins regardless of HLA genotype [12].

Feeding practices during childhood have been extensively researched, and the higher quantity of gluten in an infant's diet is associated with the development of $\mathrm{CeD}$ [13]. Time to initiation of gluten ingestion, breastfeeding, and avoidance of cow's milk do not alter the risk of developing $\mathrm{CeD}$ [14]. Certain conditions, including type 1 diabetes, $\operatorname{Ig}$ A deficiency, Down syndrome, Turner syndrome, Williams syndrome, and having a first-degree relative with $\mathrm{CeD}$, have a strong association with the illness [15].

The microbiome has been suggested to be involved in the pathogenesis of $\mathrm{CeD}$, but the current evidence is mixed [16]. An international multicenter, prospective study, called the Celiac Disease, Genomic, Environmental, Microbiome, and Metabolomic Study (CDGEMM), is currently enrolling infants genetically predisposed to $\mathrm{CeD}$ to determine the impact of microbiome-derived metabolites in its development [16].

\section{CLINICAL PRESENTATION}

Celiac disease is a highly heterogenous illness, which may have a wide spectrum of presentations. The Oslo definitions characterize the various presentations of $\mathrm{CeD}$. The expert consensus discourages the use of certain terms, including atypical $\mathrm{CeD}$, latent $\mathrm{CeD}$, typical $\mathrm{CeD}$, and silent $\mathrm{CeD}$, given their imprecise definitions [11]. Instead, it recommends the use of five classifications, including classical $\mathrm{CeD}$, nonclassical $\mathrm{CeD}$, asymptomatic $\mathrm{CeD}$, symptomatic $\mathrm{CeD}$, and subclinical $\mathrm{CeD}$ [11].

Patients with classical $\mathrm{CeD}$ present with signs and symptoms of malabsorption, such as diarrhea, steatorrhea, failure to grow, or weight loss. In contrast, patients with non-classical CeD present without malabsorption, and usually experience a monosymptomatic disease without diarrhea or steatorrhea. These patients may present with chronic abdominal pain and constipation, but without malabsorption.

Patients with asymptomatic $\mathrm{CeD}$ are discovered usually through screening programs of high-risk individuals [11]. Minor symptoms, including fatigue, may be recognized after the initiation of a gluten-free diet (GFD). Subclinical $\mathrm{CeD}$ has been defined as a disease state with symptoms or signs below the threshold required for clinical detection. Patients with subclinical CeD may present with abnormal laboratory results, including iron deficiency anemia, elevated aminotransferases, osteoporosis, enamel defects, or incidental findings on upper endoscopy. Additionally, they may present with only extragastrointestinal symptoms (Table 1). Finally, symptomatic $\mathrm{CeD}$ has been defined as clinically evident disease that manifests as gastrointestinal and/or extra-gastrointestinal symptoms related to gluten intake. 
Table 1

Extra-gastrointestinal manifestations of celiac disease

\begin{tabular}{|l|l|}
\hline \multicolumn{2}{|c|}{$\begin{array}{c}\text { Extra-Gastrointestinal } \\
\text { manifestations of celiac disease }\end{array}$} \\
\hline Constitutional & Fatigue \\
\hline Dermatologic & Dermatitis herpetiformis \\
\hline Endocrinologic & Miscarriage, delayed puberty \\
\hline Hematologic & Iron deficiency anemia \\
\hline Liver & Elevated aminotransferases \\
\hline Musculoskeletal & Arthritis, osteopenia \\
\hline Neurological & Ataxia, peripheral neuropathy, seizures \\
\hline Oncologic & T cell lymphoma \\
\hline Oral & $\begin{array}{l}\text { Aphthous ulcers, dental enamel } \\
\text { hyperplasia }\end{array}$ \\
\hline
\end{tabular}

A number of neurological manifestations may occur with CeD. ${ }^{11}$ Gluten ataxia is defined as idiopathic sporadic ataxia that occurs in patients with positive anti-gliadin antibodies with or without enteropathy [17]. CEC syndrome is rare and characterized by celiac disease (C), epilepsy (E), and cerebral calcifications (C) [18]. Vitamin deficiencies (folate and vitamin B12) from malabsorption underlie the mechanisms of gluten ataxia and CEC syndrome.

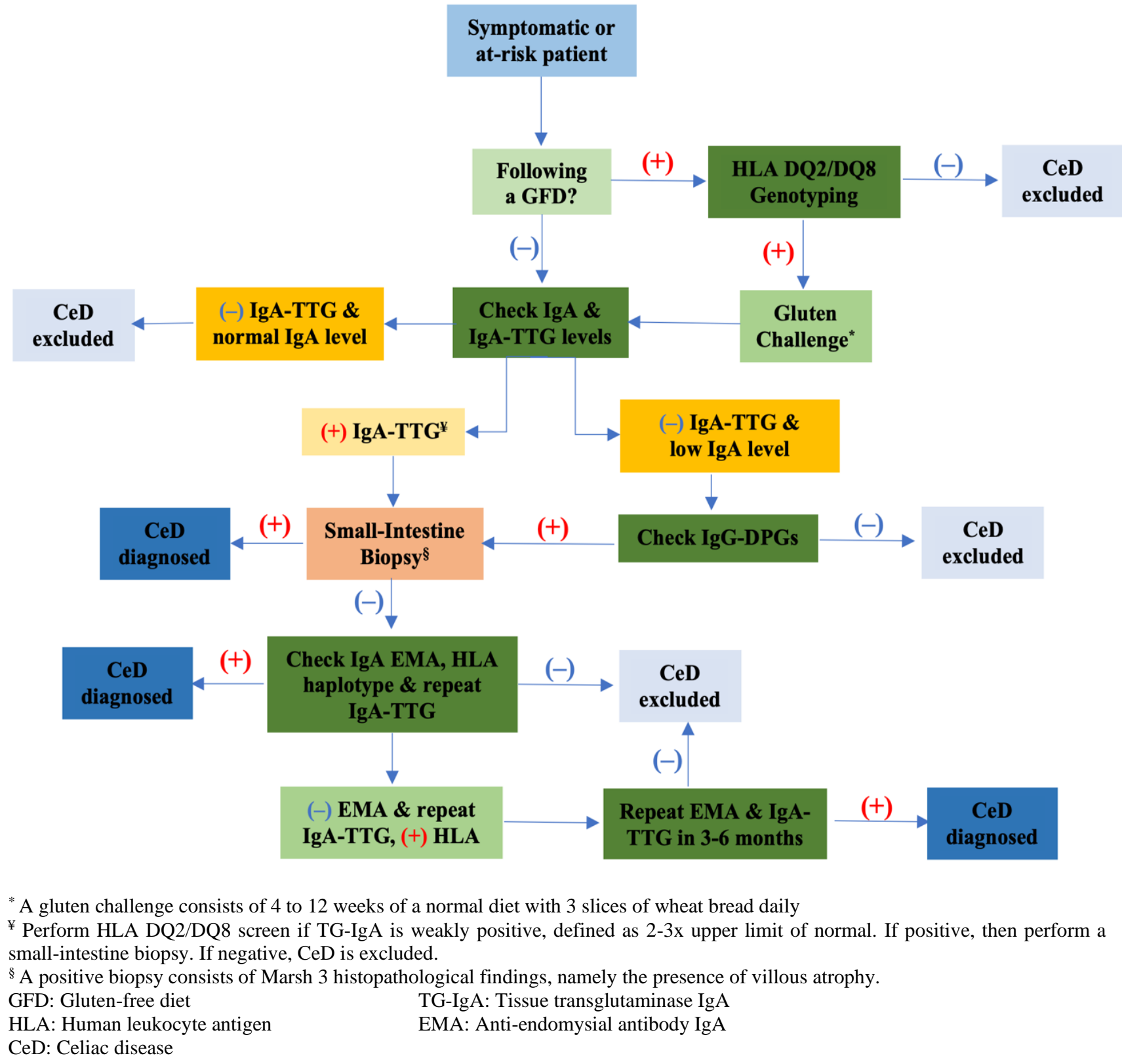

Figure 1. Diagnostic algorithm for symptomatic or at-risk individuals. 


\section{DIAGNOSTIC EVALUATION}

\section{Whom to test?}

1. Test patients with symptoms, signs, or laboratory findings suggestive of malabsorption, including diarrhea, steatorrhea, bloating, or weight loss $[19,20]$.

2. Screen first-degree relatives of patients diagnosed with $\mathrm{CeD}$ via serological testing, who present with probable signs and symptoms of $\mathrm{CeD}$ [19, 20].

3. Consider screening asymptomatic firstdegree relatives of patients diagnosed with $\mathrm{CeD}$ $[19,20]$.

4. Test patients with type 1 diabetes if they have gastrointestinal symptoms suggestive of $\mathrm{CeD}$, or in patients with elevated aminotransferases without a clear etiology [19, 20].

\section{How to test?}

IgA-TTG is the preferred first-line screening test for CeD [19]. Total IgA levels should be obtained concomitantly to determine if concurrent $\operatorname{IgA}$ deficiency exists as it is present in $2-3 \%$ of patients with $\mathrm{CeD}$ and may result in a false-negative result [21]. Ideally, testing should be obtained while the patient is following an unrestricted diet as a GFD prior to testing may give a false-negative result. Testing of HLA DQ2/DQ8 genotypes should be performed to exclude $\mathrm{CeD}$ in this scenario. Patients with positive HLA testing should have a gluten challenge consisting of 3 slices of wheat bread daily ( 3 g gluten daily) for 4-12 weeks and then retested for IgA-TTG [22].

If IgA levels are normal, and titers of $\operatorname{IgA}$ TTG are positive, then the next step involves an upper endoscopy with duodenal biopsies. If $\operatorname{IgA}$ levels are normal, but titers of IgA-TTG are negative, then $\mathrm{CeD}$ is excluded. If IgA-TTG levels are weakly positive, however, then duodenal biopsies are warranted [22]. If IgA levels are low, additional serological testing is indicated with immunoglobulin $\mathrm{G}(\mathrm{IgG})$ antideamidated gliadin peptides (DPGs). If IgG-DPG is negative, then $\mathrm{CeD}$ is excluded. If positive, then duodenal biopsies are indicated. If there is a high suspicion for $\mathrm{CeD}$ despite a negative IgA-TTG with normal $\operatorname{IgA}$ levels, i.e., seronegative $\mathrm{CeD}$, then duodenal biopsies are recommended [22].

The American College of Gastroenterology (ACG) guidelines recommend duodenal biopsies as a critical component in the diagnosis of $\mathrm{CeD}$, including 2 from the duodenal bulb (9 o'clock and 12 o'clock positions) and at least 4 from the distal duodenum [19]. The histopathological findings of $\mathrm{CeD}$ are threefold, and involve intraepithelial lymphocytes, crypt hyperplasia, and villous atrophy. Three classification criteria are used to grade the histopathological findings in $\mathrm{CeD}$, and include the Marsh, modified Marsh, and Corraza classifications. The presence of villous atrophy separates a positive from a negative biopsy.

In cases with discordant results between the biopsy and serological tests, additional testing is indicated [19]. If the biopsy is equivocal (Marsh 1 to 2 , i.e., absence of villous atrophy), HLADQ2/DQ8 genotyping is indicated. A negative HLA result excludes $\mathrm{CeD}$ given its high negative predictive value, whereas a positive result maintains $\mathrm{CeD}$ as a possibility [10]. In cases of negative serological testing but a positive biopsy, then other causes of villous atrophy should be considered and excluded before further considering CeD [19]. Anti-endomysial antibody (EMA) testing is primarily used in cases of discordant results, and may be used with HLAgenotyping and repeating IgA-TTG if biopsy results are negative [23].

American guidelines, including from the ACG and the North American Society of Pediatric Gastroenterology, Hepatology, and Nutrition (NASPGHAN), recommend obtaining a duodenal biopsy as the confirmatory test for $\mathrm{CeD}[15,19]$. The European Society of Pediatric Gastroenterology, Hepatology, and Nutrition (ESPGHAN) guidelines, however, provides an alternative approach to diagnosing $\mathrm{CeD}$ without a biopsy in pediatric patients by using a quantitative test of IgA-TTG for first-line screening [24]. If IgA-TTG titers exceed 10 times the upper limit of normal in a symptomatic pediatric patient, then a second blood sample should be tested for EMA, repeat IgA-TTG, and HLADQ2/DQ8 [24]. If the IgA-TTG persistently exceeds 10 times the upper limit of normal, and the EMA is positive, then $\mathrm{CeD}$ can be diagnosed.

A recent prospective study showed a small bowel biopsy may not be required in pediatric patients with strong serological evidence of $\mathrm{CeD}$ as proposed by the ESPGHAN guidelines [25]. The presence of any symptom, an IgA-TTG titer greater than 10 times the upper limit of normal, and a positive EMA, had a positive predictive value (PPV) for CeD of $99.75 \%$ The PPV was $100 \%$ when malabsorption was used as the only 
symptom. Additionally, it found the inclusion of HLA genotyping did not improve the accuracy of the diagnostic algorithm. This biopsy-sparing approach would decrease the need of an upper endoscopy by $30-50 \%$ [25]. The American Gastroenterological Association (AGA) released a clinical practice update of the utility of diagnostic testing and suggested a biopsy-avoiding diagnostic pathway based of this approach [26]. Nonetheless, the AGA suggests considering an upper endoscopy with duodenal biopsies in adults to evaluate for the differential diagnosis.

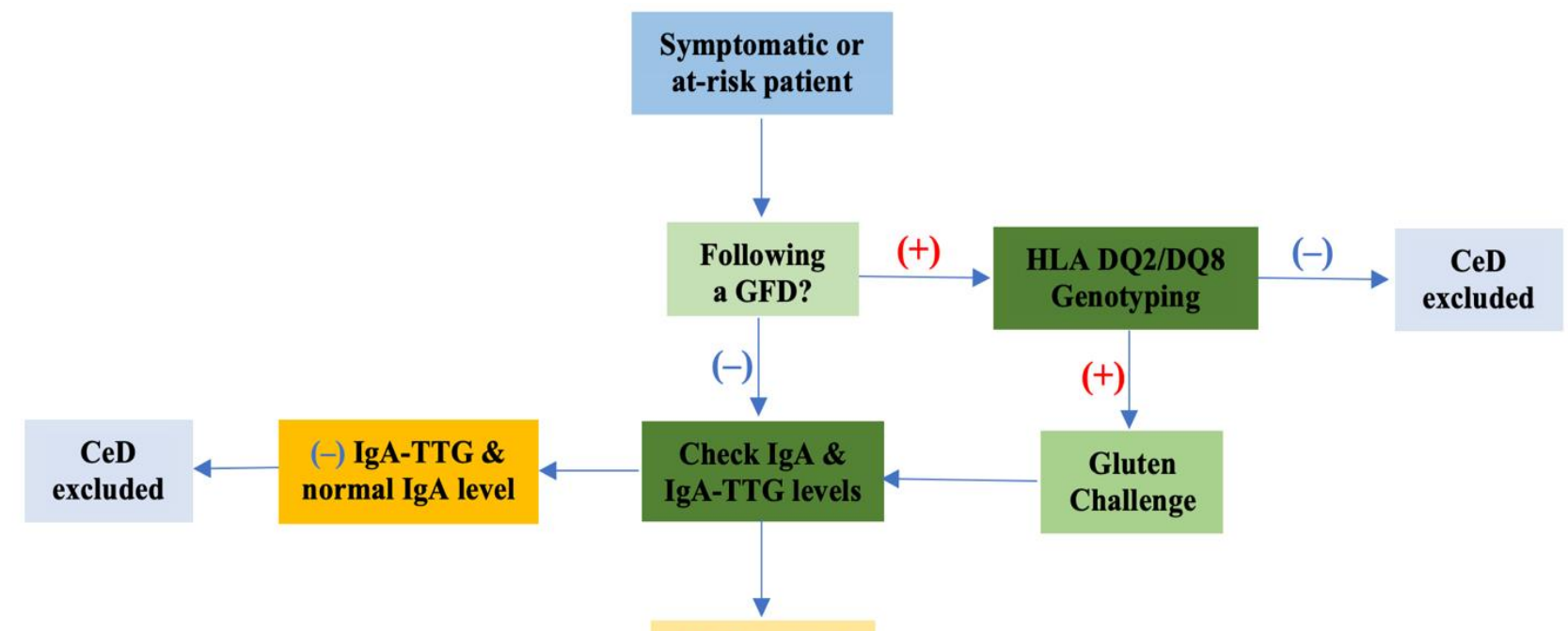

(+) IgA-TTG

$(+)$

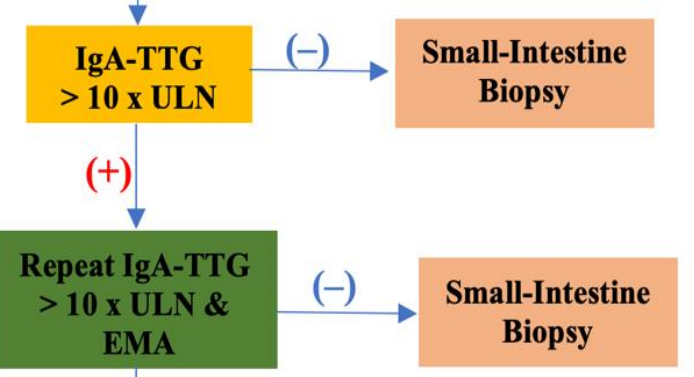

$(+)$

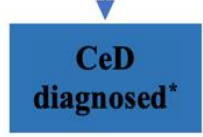

* Prospective studies have validated the biopsy-avoiding approach in pediatric pa
tients. AGA Best Practice Advise 2a supports the biopsy-avoiding approach given its posti
proceeding with upper endoscopy in adults for differential diagnosis
$\begin{array}{ll}\text { GFD: Gluten-free diet } & \text { TG-IgA: Tissue transglutaminase IgA } \\ \text { HLA: Human leukocyte antigen } & \text { EMA: Anti-endomysial antibody IgA } \\ \text { CeD: Celiac disease } & \text { ULN: Upper limit of normal }\end{array}$

Figure 2. Biopsy-avoiding diagnostic algorithm for symptomatic or at-risk individuals.

\section{Celiac disease versus non-celiac gluten sensitivity}

The Oslo definitions for celiac disease defined the illness as "a chronic small intestinal immune-mediated enteropathy precipitated by exposure to dietary gluten in genetically predisposed individuals" [11]. Additionally, it defined CeD as a permanent condition which leads to mucosal pathology and reverses with the avoidance of dietary gluten [11]. The expert consensus defined the umbrella term "gluten-related disorders" as all 
diseases precipitated by dietary gluten exposure and discouraged the use of gluten intolerance or gluten sensitivity as being synonymous with CeD. Instead, the group defined the term "nonceliac gluten sensitivity (NCGS)" to describe a set of manifestations, either immunological, morphological, or symptomatic, that arises from gluten ingestion in patients where $\mathrm{CeD}$ has been excluded.

To distinguish between CeD and NCGS, the expert consensus recommended a systematic evaluation to exclude $\mathrm{CeD}$ and other inflammatory disorders [11]. Similar to $\mathrm{CeD}$, gastrointestinal and extra-gastrointestinal manifestations may occur in NCGS, which improve with the abstinence of gluten. In contrast to CeD, NCGS lacks the presence of an enteropathy, genetic predisposition, and autoantibodies. Negative serological testing with total $\operatorname{IgA}$ and anti-TTG antibody, and a negative small intestinal biopsy are recommended to distinguish NCGS from CeD. Separating CeD from NCGS is important as it determines the longterm treatment and management of patients as NCGS has been implicated to be a transient condition [27]. In patients with NCGS, expert consensus recommends a GFD for 12 to 24 months before reassessing for gluten intolerance [27]. In contrast, patients with $\mathrm{CeD}$ must follow a lifelong and strict GFD.

\section{Treatment approach}

The mainstay of treatment for $\mathrm{CeD}$ involves adhering to a strict GFD indefinitely [19]. Following a strict GFD may be challenging as gluten may be present at small amounts in medications, supplements, or food [22]. Although studies have found a possible role of probiotics as an adjunctive therapy in $\mathrm{CeD}$, current guidelines do not recommend their use [4]. Recommendations suggest referring patients to dieticians and to pharmacists [19]. In addition to wheat, barley, and rye, patients should be advised to avoid oats for the first year following diagnosis because of cross-sensitivity [22]. In children, adhering to a strict GFD is of upmost importance as it will lead to normal growth and development, and avoidance of complications [19].

\section{COMPLICATIONS}

Adhering to a strict GFD leads to resolution of symptoms, mucosal healing, and avoidance of complications in the majority of cases [19].
Complications, including risk of malignancy and mortality, may arise in those patients who fail to adhere to a GFD, and consist of small-bowel adenocarcinoma, esophageal cancer, and intestinal T-cell lymphoma [19]. Nutritional deficiency secondary to decreased absorption of micronutrients, including iron, folate, vitamin D, B6 and B12, and zinc, copper and carnitine, is a wellknown complication of $\mathrm{CeD}$ [19]. Osteoporosis, infertility, spontaneous abortions, and pre-term labor have also been shown to occur at higher rates in patients with $\mathrm{CeD}$ [19]. Given the numerous complications that are possible if patients fail to adhere to a strict GFD, routine follow-up visits are strongly recommended in patients with CeD [19].

\section{SURVEILLANCE \& FOLLOW-UP}

The first return visit should occur at 3-6 months following the diagnosis of $\mathrm{CeD}$ and should involve determining the patient's level of adherence to a GFD, symptom resolution, and performing repeat serological testing, including IgA-TTG or IgG-DGPs. Additional tests at this visit may include a complete blood count, liver function tests, and testing for micronutrients, such as copper, zinc, vitamins A, D, E, and B12, folic acid, iron, ferritin, and carotene. Eighty percent of patients will test negative for IgA-TTG after 6-12 months of adhering to a strict GFD [28]. After being on a strict GFD for 5 years, $90 \%$ of patients will have negative serological testing [19]. Additionally, symptom improvement may be expected by the first follow-up visit [19]. Mucosal healing is expected within 1-2 years of following a GFD. Therefore, a follow up duodenal biopsy is not generally recommended if patients are adherent to a GFD. [19] If patients fail to improve or have an inadequate response (i.e., no improvement of symptoms or lack of decrease in serological titers) at the first visit, then the patient should be referred to a dietician and the clinical response should be monitored at the next visit. The role of the dietician is to evaluate for unintentional ingestion of gluten by reviewing the patient's diet habits. After six months of follow-up, subsequent visits may occur annually in patients who are strictly adhering to a GFD. Follow up duodenal biopsies are indicated in two scenarios, 1) in patients with potential $\mathrm{CeD}$ defined as having positive serologies but negative duodenal biopsies, and 2) to evaluate for an inadequate response, as discussed below. [19] 


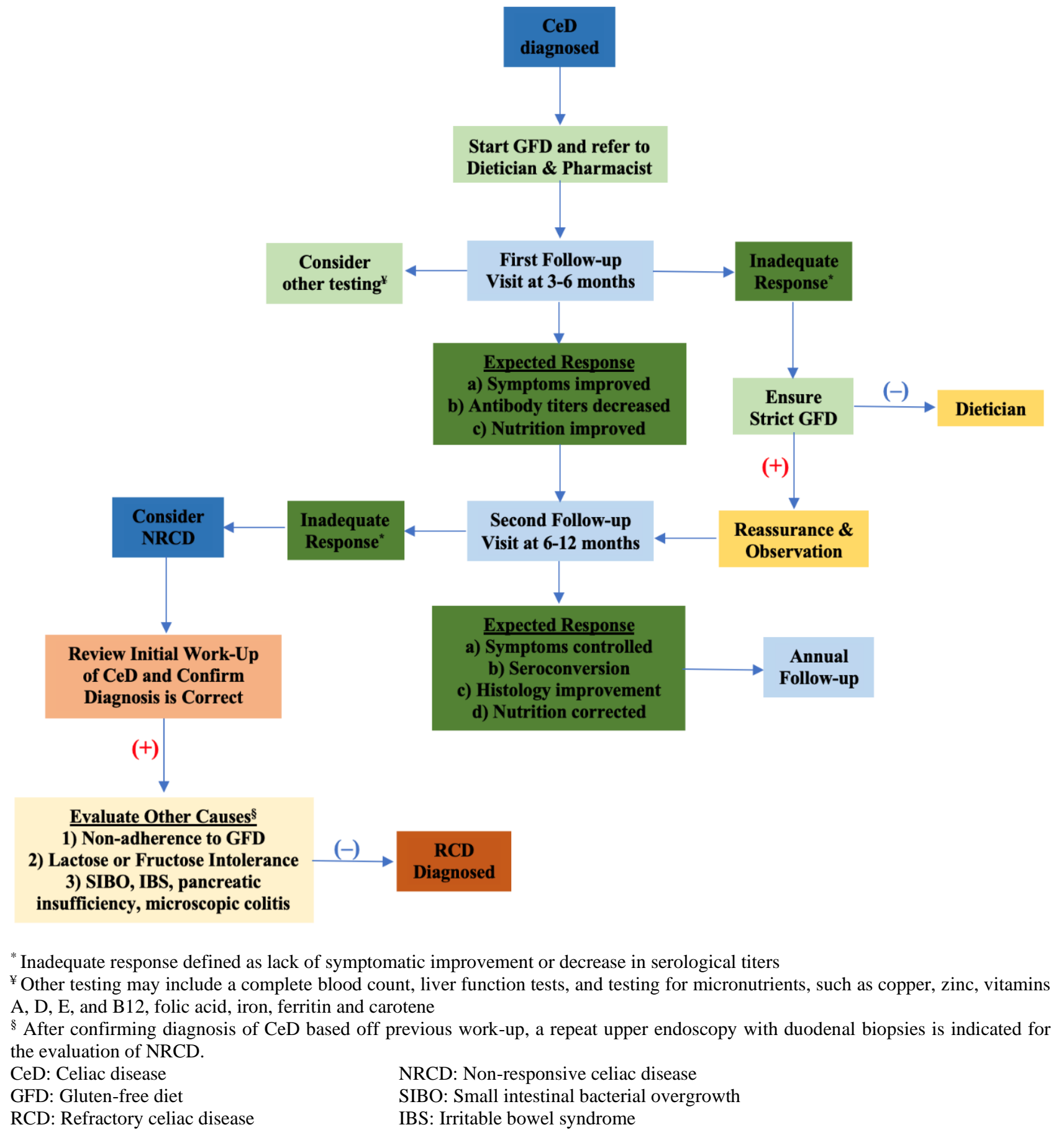

Figure 3. Surveillance and follow-up of patients with celiac disease.

\section{NON-RESPONSIVE AND REFRACTORY CELIAC DISEASE}

If an inadequate response is observed, then non-responsive celiac disease (NRCD) should be suspected. NRCD is defined as persistent symptoms despite following a strict
GFD for 6-12 months and occurs in 7 to $30 \%$ of patients [29, 30]. The most common causes of NRCD are the unintentional ingestion of gluten, followed by other food intolerances, including lactose or fructose intolerance $[29,30]$. Other considerations include small intestinal bacterial overgrowth (SIBO), pancreatic insufficiency, 
irritable bowel syndrome (IBS), microscopic colitis, and refractory $\mathrm{CeD}[29,30]$. After reviewing the initial results that confirmed $\mathrm{CeD}$, and excluding the other possible causes for NRCD, a repeat biopsy is indicated, which would show ongoing lymphocytic inflammation with villous atrophy [19]. Other causes of villous atrophy, such as autoimmune enteropathy, drug-induced enteropathy (olmesartan), intestinal lymphoma, infectious enteritis, Whipple disease, tropical sprue, hypergammaglobulinemic sprue, intestinal tuberculosis, acquired immune deficiency syndrome (AIDS) enteropathy, should be considered and evaluated if indicated [19]. The treatment approach to NRCD should be directed against the underlying etiology if discovered [19].

Refractory CeD (RCD) is defined as persistent symptoms of malabsorption despite following a strict GFD for at least 12 months with biopsy showing villous atrophy in the absence of other causes [19]. It is uncommon occurring in 1 to $2 \%$ of patients with $\mathrm{CeD}$ [31]. There are two types of RCD: Type I and Type II, which differs by the presence of CD3 T-cells with abnormal immunophenotype expression, including the lack of CD8 [31]. Treatment of RCD is not well established and involves using immunesuppressive medications, including glucocorticoids (budesonide), immunemodulators (azathioprine), monoclonal antibodies (anti-tumor necrosis factor agents) in addition to a GFD [19]. Nutritional support with total parenteral nutrition (TPN) may be implemented. Type II RCD carries a worse prognosis than Type I as it is less likely to respond [31]. Additionally, the 5-year survival of Type II RCD as compared to Type I, was $44 \%$ and 93, respectively [31]. Experimental treatments for Type II RCD have included bone marrow transplantation, anti-TNF agents, and cyclosporine [19, 31].

\section{HORIZONS}

A GFD may not resolve the gastrointestinal and extra-gastrointestinal symptoms associated with $\mathrm{CeD}$ as 7 to $30 \%$ of patients do not respond initially $[4,30]$. Gluten is ubiquitous in the food preparation industry and can be found in trace amounts in unsuspecting areas. The strict observance of a GFD may be difficult and adherence rates plummets to $35 \%$ at four years after diagnosis [32]. Additionally, about $20 \%$ of adults develop therapy-resistant $\mathrm{CeD}$ despite being adherent to a GFD [33]. Given the limitations of the GFD, additional therapies for $\mathrm{CeD}$ are being developed.

Novel nondietary therapies for $\mathrm{CeD}$ target its pathogenesis and include endopeptidases, gluten-sequestering polymers, and tight junction modulators. Endopeptidases are enzymes that catalyze the post-proline hydrolysis of peptides and reduce the immunogenicity of gluten [4]. Randomized clinical trials on these agents have shown mixed results with one trial demonstrating improvements in mucosal inflammation and clinical symptoms after 6 weeks on the highest dose of latiglutenase when compared to placebo [4]. BL-7010 is a nonabsorbable polymer that sequesters intraluminal gliadin and prevents its degradation, which has been found to reduce gluten associated histological changes in a mouse model of $\mathrm{CeD}$ [4]. A phase I/II clinical trial of BL-7010 has been completed but results have not been published (NCT01990885). Larazotide is an octopeptide similar to the zona occludens toxin of Vibrio cholerae that stabilizes the tight junctions of the small bowel and prevent gliadin-induced permeability changes [34]. Randomized trials of larazotide have shown promising results with patients reporting symptomatic improvement when coupled with GFD [4]. Other therapies target the immunogenic pathways of gliadin presentation on T-cells to prevent or decrease the adaptative immune response. These agents are under investigation, and include HLA-DQ2/-DQ8 blockers, interleukin and CD-3/CD-20 antagonists, and chemokine receptor inhibitors [4]. Another potential treatment being explored is fecal microbiota transplantation (FMT) given the role of the microbiome on the pathogenesis of $\mathrm{CeD}$ [35-37]. Several randomized trials (NCT04706611, NCT04014413) are underway and seek to address the safety and efficacy of FMT in several diseases, including CeD.

\section{CONCLUSION}

Primary care providers are essential in the diagnosis and management of patients with $\mathrm{CeD}$. We believe this comprehensive review will facilitate the understanding of the evidence behind the diagnosis and management of $\mathrm{CeD}$. 
Boala celiacă este o boală autoimună mediată de expunerea la gluten la pacienții susceptibili genetic. Este caracterizată prin infiltrat inflamator al intestinului subțire ce duce la atrofie viloasă și complicațiile asociate. Prevalența globală a bolii este în creștere mai ales datorită screening-ului și a criteriilor de diagnostic simplificate. Sunt în curs de dezvoltare noi opțiuni terapeutice, printre care agenți sechestranți, imunoterapii și enzime proteolitice. Dieta strictă fără gluten rămâne prima opțiune de tratament. În acest articol sunt trecute în revistă epidemiologia, definiția, diagnosticul și tratamentul bolii celiace.

Correspondence to: Yan Bi, MD, PhD, Mayo Clinic Jacksonville, FL 32224.

Email: Bi.Yan@mayo.edu

Tel: +1 904-953-6970

FAX: +1 904-953-6225

Conflict of interest disclosure: The authors declare no conflicts of interest.

\section{REFERENCES}

1. FREEMAN HJ. Celiac disease: a disorder emerging from antiquity, its evolving classification and risk, and potential new treatment paradigms. Gut Liver. 2015;9(1):28-37.

2. GUANDALINI S., ASSIRI A. Celiac disease: a review. JAMA Pediatr. 2014;168(3):272-278.

3. FASANO A., CATASSI C. Clinical practice. Celiac disease. N Engl J Med. 2012;367(25):2419-2426.

4. ALHASSAN E., YADAV E., YADAV A., KELLY CP. Novel Nondietary Therapies for Celiac Disease. Cell Mol Gastroenterol Hepatol. 2019;8(3):335-345.

5. GUJRAL N., FREEMAN HJ., THOMSON AB. Celiac disease: prevalence, diagnosis, pathogenesis and treatment. World J Gastroenterol. 2012;18(42):6036-6059.

6. FASANO A., BERTI I., GERARDUZZI T., NOT T., COLLETTI RB., DRAGO S., et al. Prevalence of celiac disease in at-risk and not-at-risk groups in the United States: a large multicenter study. Arch Intern Med. 2003;163(3):286-292.

7. MARDINI HE., WESTGATE P., GRIGORIAN AY. Racial Differences in the Prevalence of Celiac Disease in the US Population: National Health and Nutrition Examination Survey (NHANES) 2009-2012. Dig Dis Sci. 2015;60(6):1738-1742.

8. WEST J., FLEMING KM., TAT LJ., CARD TR., CROOKS CJ. Incidence and prevalence of celiac disease and dermatitis herpetiformis in the UK over two decades: population-based study. Am J Gastroenterol. 2014;109(5):757-768.

9. SINGH P., ARORA A., STRAND TA., LEFFLER DA., CATASSI C., GREEN PT., et al. Global Prevalence of Celiac Disease: Systematic Review and Meta-analysis. Clin Gastroenterol Hepatol. 2018;16(6):823-836.e822.

10. PALLAV K., KABBANI T., TARIQ S., VANGA R., KELLY CP., LEFFLER DA. Clinical utility of celiac disease-associated HLA testing. Dig Dis Sci. 2014;59(9):2199-2206.

11. LUDVIGSSON JF., LEFFLER DA., BAI JC., BIAGI F., FASANO A., GREEN PT., et al. The Oslo definitions for coeliac disease and related terms. Gut. 2013;62(1):43-52.

12. NiSTICO L., FAGNANI C., COTO I., PERCOPO S., COTICHINI R., LIMONGELLI MG., et al. Concordance, disease progression, and heritability of coeliac disease in Italian twins. Gut. 2006;55(6):803-808.

13. ANDREN ARONSSON C., LEE HS., HARD AF SEGERSTAD EM., UUSITALO U., YANG J., KOLETZKO S., et al. Association of Gluten Intake During the First 5 Years of Life With Incidence of Celiac Disease Autoimmunity and Celiac Disease Among Children at Increased Risk. JAMA. 2019;322(6):514-523.

14. HYYTINEN M., SAVILAHTI E., VIRTANEN SM., HARKONEN T., ILONEN J., LUOPAJARVI K., et al. Avoidance of Cow's Milk-Based Formula for At-Risk Infants Does Not Reduce Development of Celiac Disease: A Randomized Controlled Trial. Gastroenterology. 2017;153(4):961-970.e963.

15. HILL ID., DIRKS HM., LIPTAK GS., COLLETTI RB., FASANO A., GUANDALINI S., et al. Guideline for the diagnosis and treatment of celiac disease in children: recommendations of the North American Society for Pediatric Gastroenterology, Hepatology and Nutrition. J Pediatr Gastroenterol Nutr. 2005;40(1):1-19.

16. VALITUTTI F., CUCCHIARA S., FASANO A. Celiac Disease and the Microbiome. Nutrients. 2019;11(10).

17. HADJIVASSILIOUS M., SANDERS DS., GRUNEWALD RA., WOODROOFE N., BOSCOLO S., AESCHLIMANN. Gluten sensitivity: from gut to brain. Lancet Neurol. 2010;9(3):318-330.

18. CURY RG., HOBI MOREIRA C. Images in clinical medicine. Occipital calcification and celiac disease. N Engl J Med. 2014;370(16):e26.

19. RUBIO-TAPIA A., HILl ID., KELlY CP., CALDERWOOD AH., MURRAY JA. GASTROENTEROLOGY ACO. ACG clinical guidelines: diagnosis and management of celiac disease. Am J Gastroenterol. 2013;108(5):656-676; quiz 677.

20. BIBBINS-DOMINGO K., GROSSMAN DC., CURRY SJ., BARRY MJ., DAVIDSON KW., DOUBENI CK., et al. Screening for Celiac Disease: US Preventive Services Task Force Recommendation Statement. JAMA. 2017;317(12):1252-1257.

21. MCGOWAN KE., LYON ME., BUTZNER JD. Celiac disease and IgA deficiency: complications of serological testing approaches encountered in the clinic. Clin Chem. 2008;54(7):1203-1209. 
22. OXENTENKO AS., MURRAY IA. Celiac Disease: Ten Things That Every Gastroenterologist Should Know. Clin Gastroenterol Hepatol. 2015;13(8):1396-1404; quiz e1127-1399.

23. ROSTOM A., DUBE C., CRANNEY A., SALOOJEE N., SY R., GARRITTY C., et al. The diagnostic accuracy of serologic tests for celiac disease: a systematic review. Gastroenterology. 2005;128(4 Suppl 1):S38-46.

24. HUSBY S., KOLETZKO S., KORPONAY-SZABO., KURPPA K., MEARIN ML., RIBES-KONINCKX C., et al. European Society Paediatric Gastroenterology, Hepatology and Nutrition Guidelines for Diagnosing Coeliac Disease 2020. J Pediatr Gastroenterol Nutr. 2020;70(1):141-156.

25. WERKSTETTER KJ., KORPONAY-SZABO IR., POPP A., VILLANACCI V., SALEMME M., HEILIG G., et al. Accuracy in Diagnosis of Celiac Disease Without Biopsies in Clinical Practice. Gastroenterology. 2017;153(4):924-935.

26. HUSBY S., KOLETZKO S., KORPONAY-SZABO IR., MEARIN ML., PHILLIPS A., SHAMIR R., et al. European Society for Pediatric Gastroenterology, Hepatology, and Nutrition guidelines for the diagnosis of coeliac disease. J Pediatr Gastroenterol Nutr. 2012;54(1):136-160.

27. FASANO A., SAPONE A., ZEVALlOS V., SCHUPPAN D. Nonceliac gluten sensitivity. Gastroenterology. 2015;148(6):1195-1204.

28. RASHTAK S., ETTORE MW., HOMBURGER HA., MURRAY JA. Comparative usefulness of deamidated gliadin antibodies in the diagnosis of celiac disease. Clin Gastroenterol Hepatol. 2008;6(4):426-432; quiz 370.

29. ABDULKARIM AS., BURGART LJ., SEE J., MURRAY JA. Etiology of nonresponsive celiac disease: results of a systematic approach. Am J Gastroenterol. 2002;97(8):2016-2021.

30. LEFFLER DA., DENNIS M., HYETT B., KELLY E., SCHUPPAN D., KELLY CP. Etiologies and predictors of diagnosis in nonresponsive celiac disease. Clin Gastroenterol Hepatol. 2007;5(4):445-450.

31. MALAMUT G., AFCHAIN P., VERKARRE V., LECOMTE T., AMIOT A., DAMOTTE D., et al. Presentation and long-term follow-up of refractory celiac disease: comparison of type I with type II. Gastroenterology. 2009;136(1):81-90.

32. HERMAN ML., RUBIO-TAPIA A., LAHR BD., LARSON JJ., VAN DYKE CT., MURRAY JA. Patients with celiac disease are not followed up adequately. Clin Gastroenterol Hepatol. 2012;10(8):893-899.e891.

33. RUBIO-TAPIA A., RAHIM MW., SEE JA., LAHR BD., WU TT., MURRAY JA. Mucosal recovery and mortality in adults with celiac disease after treatment with a gluten-free diet. Am J Gastroenterol. 2010;105(6):1412-1420.

34. PATERSON B., LAMMERS KM., ARRIETA. MC., FASANO A., MEDDINGS JB. The safety, tolerance, pharmacokinetic and pharmacodynamic effects of single doses of AT-1001 in coeliac disease subjects: a proof of concept study. Aliment Pharmacol Ther. 2007;26(5):757-766.

35. GOLFEYZ S. Celiac Disease and Fecal Microbiota Transplantation: A New Beginning? Am J Gastroenterol. 2018;113(8):1256.

36. LEBWOHL B., NOBEL YR., GREEN PHR., BLASER MJ., LUDVIGSSON JF. Risk of Clostridium difficile Infection in Patients With Celiac Disease: A Population-Based Study. Am J Gastroenterol. 2017;112(12):1878-1884.

37. VAN BEURDEN YH., VAN GILS T., VAN GILS NA., KASSAM Z., MULDER CJ., APARICIO-PAGES N. Serendipity in Refractory Celiac Disease: Full Recovery of Duodenal Villi and Clinical Symptoms after Fecal Microbiota Transfer. J Gastrointestin Liver Dis. 2016;25(3):385-388.

Received $6^{\text {th }}$ December 2021 